\title{
Microalgal biomass production pathways: evaluation of life cycle environmental impacts
}

\author{
George G Zaimes and Vikas Khanna*
}

\begin{abstract}
Background: Microalgae are touted as an attractive alternative to traditional forms of biomass for biofuel production, due to high productivity, ability to be cultivated on marginal lands, and potential to utilize carbon dioxide $\left(\mathrm{CO}_{2}\right)$ from industrial flue gas. This work examines the fossil energy return on investment (EROI fossii $_{1}$, greenhouse gas (GHG) emissions, and direct Water Demands (WD) of producing dried algal biomass through the cultivation of microalgae in Open Raceway Ponds (ORP) for 21 geographic locations in the contiguous United States (U.S.). For each location, comprehensive life cycle assessment (LCA) is performed for multiple microalgal biomass production pathways, consisting of a combination of cultivation and harvesting options.

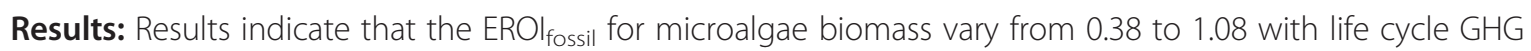
emissions of -46.2 to 48.9 ( $\mathrm{g} \mathrm{CO}_{2}$ eq/MJ-biomass) and direct WDs of 20.8 to 38.8 (Liters/MJ-biomass) over the range of scenarios analyzed. Further anaylsis reveals that the EROI fossil for production pathways is relatively location invariant, and that algae's life cycle energy balance and GHG impacts are highly dependent on cultivation and harvesting parameters. Contrarily, algae's direct water demands were found to be highly sensitive to geographic location, and thus may be a constraining factor in sustainable algal-derived biofuel production. Additionally, scenarios with promising $\mathrm{EROI}_{\text {fossil }}$ and $\mathrm{GHG}$ emissions profiles are plagued with high technological uncertainty.

Conclusions: Given the high variability in microalgae's energy and environmental performance, careful evaluation of the algae-to-fuel supply chain is necessary to ensure the long-term sustainability of emerging algal biofuel systems. Alternative production scenarios and technologies may have the potential to reduce the critical demands of biomass production, and should be considered to make algae a viable and more efficient biofuel alternative.
\end{abstract}

Keywords: Microalgae, Biomass, Bioenergy, Biofuel, Life cycle analysis, Chlorella vulgaris, Open raceway ponds, GHG emissions, Water demands

\section{Background}

Heightened global awareness of climate change and consumption of finite resources has driven research in biomass-based forms of energy production. Current fossil fuel depletion rates and related emissions have prompted development of sustainable energy alternatives that are both carbon neutral and compatible with existing infrastructure. In past years, researchers have examined various biomass feedstocks such as corn, soybean, canola, and lignocellulosic crops for their bioenergy potential. Major drawbacks to these first and second generation biofuels including land use, water footprint, and influence in global food markets

\footnotetext{
* Correspondence: khannav@pitt.edu

Department of Civil and Environmental Engineering, Swanson School of Engineering, University of Pittsburgh, Pittsburgh 15261, Pennsylvania
}

have prompted research in alternative forms of biomass [1]. Accordingly, algae-to-energy systems are receiving increased attention from both academic and industrial sectors. Microalgae's promising characteristics, such as: high productivity [2], ability to be cultivated on marginal lands [3], semi-continuous to continuous harvesting, high lipid content, and potential to utilize carbon dioxide $\left(\mathrm{CO}_{2}\right)$ from industrial flue gas make it an attractive feedstock for biofuel production [4-8]. In addition, microalgae production does not directly displace food crops, as do other leading biomass candidates such as corn or soybean [9]. In 2007, the United States (U.S.) congress passed the Energy Independence and Security Act (EISA), which mandates the production and addition of 36 billion gallons of biofuels to traditional transportation fuels by the year 2022 [10]. Extraction and subsequent upgrading 
of microalgal biomass feedstock may provide both a liquid fuel that has the potential to be compatible with current transportation fuel infrastructure, and satisfy the EISA mandate.

The prospect of utilizing microalgae for energy production is not a recent phenomenon: between 1978 and 1998 the Unites States Department of Energy's (DOE) Aquatic Species Program, a research program aimed to develop renewable transportation fuels, extensively examined the production of biodiesel from microalgae [11]. Current demand for transportation fuels, as well as technological advancements and maturation, have motivated researchers to re-examine microalgae's potential as a fuel source [12], and in recent years have led to a host of microalgae based life cycle assessments (LCA) [13-35]. Prior studies have shown that different algae harvesting options, reactor configurations, culture conditions, and cultivation assumptions yield divergent results concerning algae's environmental and energy performance [13,15,21-23,26,35,36]. As such, evaluation of the life cycle greenhouse gas (GHG) emissions, fossil energy consumption, and water demands for multiple biomass production pathways within the framework of one study can provide insight into the potential tradeoffs, environmental impacts, and technical feasibility of these pathways. As microalgal derived fuels are inherently dependent on the cultivation of microalgae feedstock, a sustainable pathway for microalgae feedstock production must be identified if algal-based fuels are to become a commercial reality. Furthermore, additional pilot testing and laboratory scale results will be necessary for validating and benchmarking theoretical process modeling [37-39]. Holistic evaluation of emerging algae-to-fuel systems that considers the resource consumption, emissions, and their impact across the entire life cycle is critical to assess the environmental sustainability of emerging algae-based energy systems.

This study examines the critical life cycle energy and environmental drivers in algae cultivation through a comprehensive analysis of a theoretical industrial algae Open Raceway Pond (ORP) facility. Prior studies have indicated that photobioreactors (PBR) have high initial capital and operating costs, which limit their commercial viability $[18,40]$. For these reasons only ORPs were investigated as a means for mass cultivation of microalgae. This work focuses on a typical process chain for ORPs: cultivation followed by a series of flocculation, dewatering, and additional drying [41]. Algal drying requirements were based on soybean production, where final biomass has a solids concentration of $90 \%$ on a weight per weight basis $(\mathrm{w} / \mathrm{w})$ [35]. Process energy and material flows were constructed based on first principles of thermodynamics, peer-reviewed literature, heat and material balances, and best available engineering knowledge. Multiple cultivation locations across the United States (U.S.) as well as cultivation and harvesting options are modeled to investigate the extent to which these parameters affect the overall energy balance, GHG emissions, and direct water demand of microalgal biomass production, and identify opportunities for process improvements along the algae supply chain.

This work models the production of microalgal biomass using freshwater algae grown using synthetic fertilizers and $\mathrm{CO}_{2}$ /flue gas from an industrial power plant. The objective of this work is to compare different technological routes for producing dried algal biomass to be used for as a feedstock for conversion to liquid transportation fuel(s). It is assumed that the biomass must be dried to $90 \%(\mathrm{w} / \mathrm{w})$ before further downstream processing of biomass-to-fuel is possible and is consistent with current commercially available lipid extraction technologies.

\section{Methodology and sustainability metrics LCA model overview}

In this study, a comparative LCA of microalgae cultivation and harvesting options for ORPs was conducted. The scope of the LCA is cradle-to-gate, in which all processes upstream of dried biomass are evaluated. With the exception of polyvinyl chloride (PVC) lining [23], previous LCA studies have shown that algae infrastructure related impacts are negligible as compared to other system processes [16], and were thus excluded from the scope of this study. The functional unit was chosen as one Megajoule (MJ) of dried algal biomass. Cultivation of microalgae was evaluated for 232 National Weather Service (NWS) sites in the continental U.S. [42]. Prior research has suggested that for ORPs, microalgae growth rates rapidly decline when exposed to average temperatures less than $15^{\circ} \mathrm{C}$ [43]. Of the 232 examined locations, 21 sites were found to have monthly average temperatures within the requisite temperature range required to support the mass cultivation of microalgae. Complete LCA was then conducted for these 21 locations, to examine if variations in regional energy mix as well as climatological and geographical parameters influence algal biomass production. For each cultivation location multiple biomass production pathways were examined, consisting of a combination of two options for $\mathrm{CO}_{2}$ procurement (Monoethanolamine (MEA) scrubbing with injection of pure $\mathrm{CO}_{2}$ or Direct Injection (DI) of industrial flue gas), two algal dewatering options (centrifugation (CF) or chamber filter press (CFP)), and two algal drying scenarios (natural gas based drying (NGD) or waste heat drying (WHD)).

\section{Sustainability metrics}

The focus of this study is to create an LCA model to evaluate the life cycle energy balance, direct water demands (WD), and net life cycle GHG emissions for the 
cultivation of microalgae in ORPs. The direct WD was evaluated as the difference between the volume of freshwater required to support algae cultivation and annual regional precipitation. Net life cycle GHG emissions were calculated as the difference between $\mathrm{CO}_{2}$ embedded in the microalgae feedstock, as carbon, to the amount of life cycle GHGs emitted throughout the biomass supply chain. As the primary motivation for microalgae production is its potential to displace fossil derived fuels, a fossil energy return on investment metric $\left(\mathrm{EROI}_{\text {fossil }}\right)$ was chosen to assess the sustainability of microalgae production. $\mathrm{EROI}_{\text {fossil }}$, is defined as the ratio of the energy stored in algal biomass (lower heating value $\mathrm{x}$ mass of biomass) to the embodied non-renewable fossil energy required to produce algal biomass, and is presented in equation 1.

$$
E R O I_{\text {fossil }}=\frac{\text { Biomass Energy Output }}{\text { Nonrenewable Fossil Energy Input }}
$$

Production pathways in which the EROI fossil $_{\text {are }}$ greater than 1 are desirable, as more biomass energy is produced than non-renewable fossil energy consumed in biomass production. As the cultivation, dewatering, and harvesting of microalgae is energy intensive and a major bottleneck in the algae-to-fuel production chain $[39,44,45]$, identifying renewable and sustainable pathways for the cultivation of microalgae is critical for the overall advancement of microalgal derived fuels. To reduce the complexity and dimensionality of the data, as well as to allow ease of comparison between different studies, the main paper will provide a detailed analysis and comparison of the net life cycle GHG emissions, direct water demands, and $\mathrm{EROI}_{\text {fossil }}$ for biomass production pathways for Phoenix, AZ. Detailed tables for $\mathrm{EROI}_{\text {fossil }}$, direct WD, and GHG emissions for all examined production pathways and locations are provided in the supporting information (see Additional file 1).

\section{Algal composition and growth rates}

An algal growth model was constructed to evaluate microalgal growth rates for ORPs in the continental U.S. Theoretical microalgae photosynthetic yields were constructed based on solar insolation values averaged over a thirty-year period (1961-1990), obtained from the National Solar Radiation Database (NSRD), and efficiency factors determined by pond design and characteristics of the algal culture $[46,47]$. The fractionated composition of the algae was assumed to be $20 \%$ lipids, $25 \%$ carbohydrates, $50 \%$ proteins, and $5 \%$ other organic material and is consistent with previous studies $[14,48]$. The composition of algae was calculated to be 517 grams (g) C, $81.2 \mathrm{~g} \mathrm{~N}$, $17.6 \mathrm{~g} \mathrm{P}$, and $14.5 \mathrm{~g} \mathrm{~K}$ per kilogram (kg) biomass. The lower heating value (LHV) of the biomass was computed to be $18.66 \mathrm{MJ} / \mathrm{kg}$-biomass.

\section{Production chain overview and data sources Production chain overview}

Figure 1 shows the microalgal biomass production chain and examined production pathways. Cultivation of the freshwater algae strain, Chlorella vulgaris, was modeled in a 1000-hectare (ha) virtual algae production facility, in which 500 ha are allocated for algae cultivation and 500 for infrastructure related demands. This virtual facility was assumed to be colocated with natural gas (NG) fired power plants, and would operate for eight months

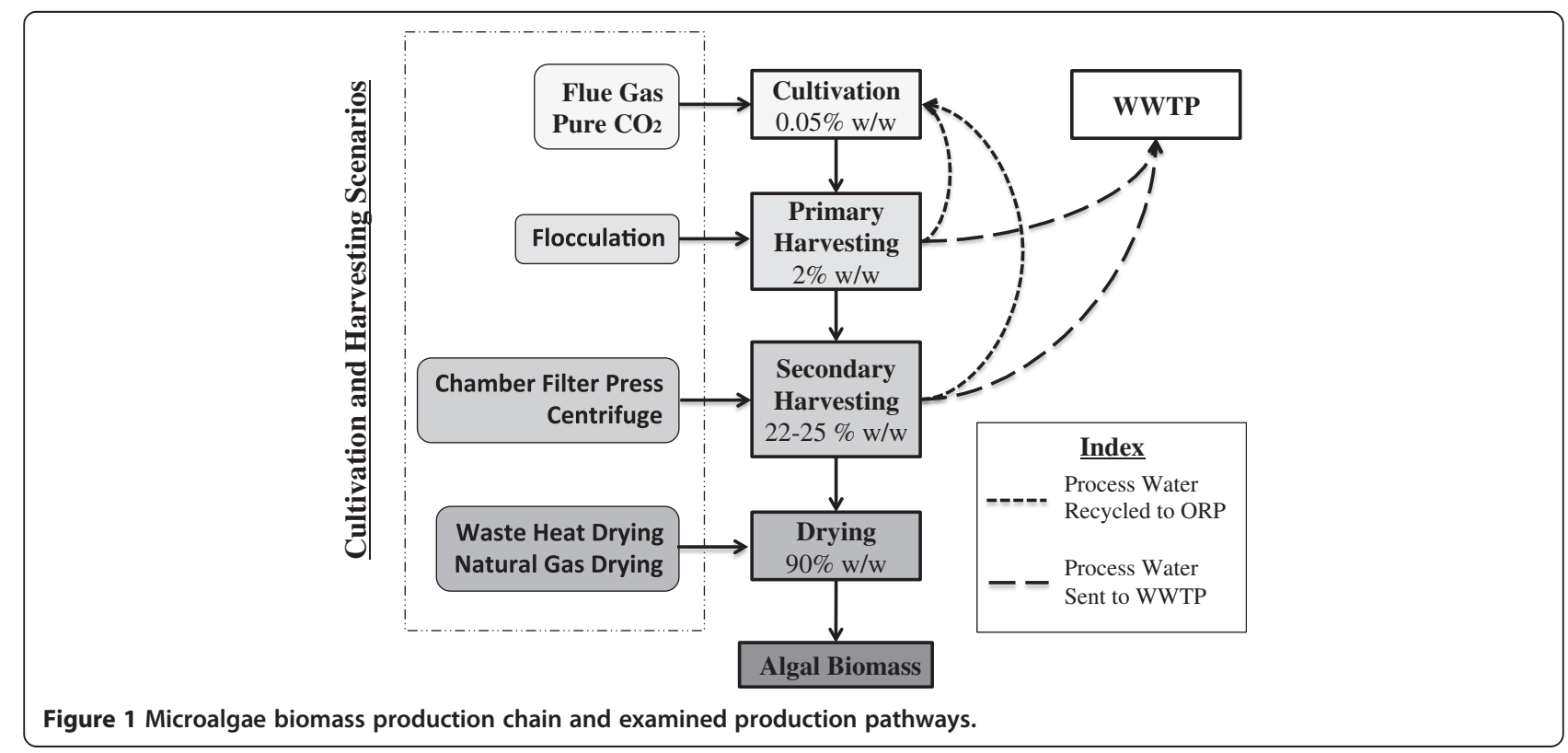


out of the year, from March to October. Comprehensive $L C A$ was performed on 21 cultivation locations, spanning seven states: $(A L, A Z, C A, F L, G A, L A, \mathcal{E} T X)$. In each of these locations, biomass production was based on cultivating algae in ORPs. Data concerning the regional electricity mix for the cultivation locations was gathered from the EPA's "Power Profiler", based off the 2007 Emissions and Generation Resource Integrated Database (eGRID) [49].

The algal cultivation area is comprised of individual 1ha ORPs, with a pond depth of 0.3 meters, and operating at an algal concentration of $0.05 \%(\mathrm{w} / \mathrm{w})[17,35]$. The algal growth medium circulates at a mixing velocity of $15 \mathrm{~cm} /$ second via paddlewheels [41]. A $0.75 \mathrm{~mm}$ thick PVC membrane lines the cultivation area [23], with an assumed average lifetime of 5 years [23]. Nutrient and fertilizer requirements were estimated based on algal growth rates and composition of the algal culture. Prior studies have differing assumptions regarding the quantity of nutrients required for algae growth, ranging from approximately one [35] to two [16] times the stoichiometric requirement. In this study a $75 \%$ nutrient use-efficiency is assumed, with nitrogen provided by synthetic urea, potassium by potassium chloride, and phosphate by superphosphate. Nutrients and fertilizers are pumped into the ponds with freshwater so that no additional mixing is required. $\mathrm{CO}_{2}$ is supplied from a nearby NG fired power plant either by the direct injection of flue gas, or by separating flue gas into pure $\mathrm{CO}_{2}$ via MEA scrubbing and delivering pure $\mathrm{CO}_{2}$ into the algae ponds [50]. Post cultivation, microalgae are sent to holding tanks, wherein a chemical flocculent, aluminum sulfate, is added to the algal culture to agglomerate the algal biomass so that it can be efficiently separated from the water matrix [51]. The flocculated algae are then sent to either an industrial centrifuge or chamber filter press to concentrate the algae by dewatering. Medium from both flocculation and dewatering stages are recycled back into the ponds to minimize the overall water demands. After dewatering, the microalgae slurry undergoes additional drying. Two scenarios were examined for algal drying. In the first scenario, microalgae are sent to an industrial boiler, in which natural gas is burned to concentrate the algae slurry. The second scenario utilizes waste heat from a colocated power plant as a means of drying the algal biomass. Life cycle data for aluminum sulfate, fertilizers, PVC, and wastewater were taken from the Ecoinvent database [52]. Life cycle data concerning electricity generation and natural gas were taken from the United States Life Cycle Inventory (USLCI) database [53]. Further information regarding algal growth rates, composition, and detailed LCI for all modeled production pathways is available in the supporting information (see Additional file 1).

\section{Water demands}

The production of biofuels has been shown to be water intensive [54-58]. Quantifying the direct component of the WD can help determine the impacts of biofuel production on regional water resources, and therefore is an important criterion for evaluating optimal locations for algal cultivation. In this study, it is assumed that ORPs are drained and the water is treated at a wastewater treatment facility once every four months to avoid buildup of bacteria and invasive microbes. Additionally, freshwater is required to be pumped into the ponds due to water loss from pond leaking, evaporation, blowdown, photosynthetic requirements, water lost during the harvesting process, algal drying, and water contained within the final biomass that is transported offsite. Water lost due to leaking from the open ponds was evaluated at a rate of $0.27 \mathrm{~m}^{3} / \mathrm{m}^{2}$-year [20]. Evaporative losses were estimated based on the Penman equation [59]. Data for wind speed $(\mathrm{m} / \mathrm{s})$, average temperature $\left({ }^{\circ} \mathrm{C}\right)$, and relative humidity (\%) averaged over a thirty year period (1961-1990) was obtained from the NSRD [42]. Data concerning average rainfall for the various locations was taken from the National Oceanic and Atmospheric Administration (NOAA) [60]. To avoid excess mineral and salt build-up, and to regulate the $\mathrm{pH}$ of the culture medium, a portion of the algal growth medium must be removed from the ponds and replaced with an equivalent amount of freshwater [61]. This process is known as "blowdown", and it was assumed that onsite evaporation ponds would be used for blowdown disposal. The chemical process of photosynthesis consumes water as a reactant; therefore freshwater that is consumed by photosynthesis in the cultivation ponds must be replaced. During the harvesting stage, process water from both flocculation and dewatering stages are recycled back into the ponds. It was assumed that only 90\% [27] of the water recycled from these stages would be returned to the ponds, the remaining $10 \%$ must be treated at a wastewater treatment plant (WWTP). Therefore, freshwater must be supplied to the ORPs to offset water that is lost during the harvesting process. Furthermore, freshwater is required to makeup the volume of water that is contained in the final algae biomass that is transported off-site. The direct WD was calculated as the difference between the volume of freshwater required to support algae cultivation and annual precipitation.

\section{Results and discussion}

\section{EROI $_{\text {fossil }}$ and life cycle GHG analysis}

Table 1 presents the direct WDs, EROI fossil $_{\text {, }}$ and net life cycle GHG emissions for all examined biomass production pathways (denoted as A-H) and locations. Table 1 reveals that the net energy balance is negative for a majority of the scenarios analysed. This indicates that 
Table 1 EROI $_{\text {fossil, }}$ net life cycle GHG emissions, and direct WDs for examined biomass production pathways \& locations

\begin{tabular}{|c|c|c|c|c|c|c|c|c|c|c|}
\hline Scenarios & $A^{*}$ & $B^{*}$ & $\mathrm{C}^{*}$ & $D^{*}$ & $E^{*}$ & $\mathrm{~F}^{*}$ & $\mathrm{G}^{*}$ & $\mathrm{H}^{*}$ & W & $D^{1}$ \\
\hline Location & $\begin{array}{l}\text { MEA/CF/ } \\
\text { NGD }\end{array}$ & $\begin{array}{l}\text { MEA/CFP/ } \\
\text { NGD }\end{array}$ & $\begin{array}{l}\mathrm{DI} / \mathrm{CF} / \\
\mathrm{NGD}\end{array}$ & $\begin{array}{c}\text { DI/CFP/ } \\
\text { NGD }\end{array}$ & $\begin{array}{c}\text { MEA/CF/ } \\
\text { WHD }\end{array}$ & $\begin{array}{l}\text { MEA/CFP/ } \\
\text { WHD }\end{array}$ & $\begin{array}{l}\mathrm{DI} / \mathrm{CF} / \\
\text { WHD }\end{array}$ & $\begin{array}{c}\text { DI/CFP/ } \\
\text { WHD }\end{array}$ & CFP & $\mathrm{CF}$ \\
\hline Mobile, AL & $0.40(44.2)$ & $0.46(22.5)$ & $0.49(18.9)$ & $0.59(-2.8)$ & $0.60(-0.4)$ & $0.68(-15.1)$ & $0.86(-25.7)$ & $1.04(-40.4)$ & 22.1 & 22.3 \\
\hline Phoenix, AZ & $0.38(48.9)$ & $0.43(28.4)$ & $0.47(23.5)$ & $0.56(3.0)$ & $0.57(4.2)$ & $0.64(-9.2)$ & $0.79(-21.2)$ & $0.94(-34.6)$ & 38.6 & 38.8 \\
\hline San Diego, CA & $0.41(32.0)$ & $0.46(16.0)$ & $0.51(6.3)$ & $0.60(-9.6)$ & $0.63(-12.6)$ & $0.69(-21.5)$ & $0.91(-38.3)$ & $1.06(-47.2)$ & 32.8 & 33.0 \\
\hline Daytona Beach, FL & $0.38(43.0)$ & $0.44(22.7)$ & $0.47(17.5)$ & $0.57(-2.7)$ & $0.58(-1.6)$ & $0.66(-14.8)$ & $0.81(-27.1)$ & $0.97(-40.2)$ & 24.1 & 24.3 \\
\hline Jacksonville, FL & $0.38(43.1)$ & $0.44(22.8)$ & $0.47(17.7)$ & $0.57(-2.6)$ & $0.58(-1.5)$ & $0.66(-14.7)$ & $0.81(-27.0)$ & $0.97(-40.1)$ & 22.6 & 22.9 \\
\hline Key West, FL & $0.38(43.6)$ & $0.44(23.4)$ & $0.47(18.2)$ & $0.57(-2.1)$ & $0.57(-1.0)$ & $0.65(-14.2)$ & $0.80(-26.4)$ & $0.97(-39.6)$ & 28.4 & 28.6 \\
\hline Miami, FL & $0.38(42.7)$ & $0.44(22.5)$ & $0.48(17.3)$ & $0.57(-3.0)$ & $0.58(-1.9)$ & $0.66(-15.1)$ & $0.81(-27.3)$ & $0.98(-40.5)$ & 22.1 & 22.4 \\
\hline Tallahassee, FL & $0.39(42.4)$ & $0.44(22.2)$ & $0.48(17.0)$ & $0.57(-3.2)$ & $0.58(-2.2)$ & $0.66(-15.4)$ & $0.82(-27.6)$ & $0.98(-40.8)$ & 20.8 & 21.1 \\
\hline Tampa, FL & $0.38(43.2)$ & $0.44(23.0)$ & $0.47(17.8)$ & $0.57(-2.5)$ & $0.58(-1.4)$ & $0.65(-14.6)$ & $0.81(-26.8)$ & $0.97(-40.0)$ & 25.1 & 25.4 \\
\hline West Palm Beach, FL & $0.38(43.0)$ & $0.44(22.7)$ & $0.47(17.6)$ & $0.57(-2.7)$ & $0.58(-1.6)$ & $0.66(-14.8)$ & $0.81(-27.0)$ & $0.97(-40.2)$ & 22.9 & 23.1 \\
\hline Savannah, GA & $0.39(45.0)$ & $0.45(23.2)$ & $0.49(19.7)$ & $0.59(-2.1)$ & $0.60(0.4)$ & $0.68(-14.3)$ & $0.86(-24.9)$ & $1.03(-39.6)$ & 24.1 & 24.4 \\
\hline Baton Rouge, LA & $0.39(39.2)$ & $0.45(20.8)$ & 0.49 (13.6) & $0.58(-4.7)$ & $0.60(-5.4)$ & $0.67(-16.8)$ & $0.86(-31.0)$ & $1.01(-42.3)$ & 22.6 & 22.8 \\
\hline Lake Charles, LA & $0.39(39.0)$ & $0.45(20.6)$ & $0.49(13.5)$ & $0.58(-4.9)$ & $0.60(-5.6)$ & $0.67(-16.9)$ & $0.86(-31.1)$ & $1.02(-42.4)$ & 23.0 & 23.2 \\
\hline New Orleans, LA & $0.40(38.9)$ & $0.45(20.5)$ & $0.49(13.4)$ & $0.58(-5.0)$ & $0.60(-5.7)$ & $0.67(-17.0)$ & $0.86(-31.2)$ & $1.02(-42.5)$ & 22.1 & 22.3 \\
\hline Austin, TX & $0.39(41.5)$ & $0.45(20.6)$ & $0.49(16.1)$ & $0.59(-4.8)$ & $0.59(-3.1)$ & $0.68(-16.9)$ & $0.85(-28.5)$ & $1.03(-42.3)$ & 29.8 & 30.0 \\
\hline Brownsville, TX & $0.39(41.8)$ & $0.45(20.9)$ & $0.49(16.4)$ & $0.58(-4.5)$ & $0.59(-2.8)$ & $0.68(-16.6)$ & $0.84(-28.2)$ & $1.02(-42.0)$ & 30.6 & 30.8 \\
\hline Corpus Christi, TX & $0.39(42.1)$ & $0.45(21.3)$ & $0.48(16.8)$ & $0.58(-4.1)$ & $0.59(-2.5)$ & $0.67(-16.3)$ & $0.84(-27.8)$ & $1.02(-41.7)$ & 29.7 & 29.9 \\
\hline Houston, TX & $0.39(42.0)$ & $0.45(21.1)$ & $0.49(16.7)$ & $0.58(-4.2)$ & $0.59(-2.6)$ & $0.67(-16.4)$ & $0.84(-27.9)$ & $1.02(-41.8)$ & 25.6 & 25.8 \\
\hline Lufkin, TX & 0.39 (41.5) & $0.45(20.6)$ & 0.49 (16.1) & $0.59(-4.8)$ & $0.59(-3.1)$ & $0.68(-16.9)$ & $0.85(-28.5)$ & $1.03(-42.3)$ & 26.1 & 26.3 \\
\hline Port Arthur, TX & $0.40(35.2)$ & $0.46(16.9)$ & $0.51(9.7)$ & $0.60(-8.6)$ & $0.62(-9.4)$ & $0.70(-20.6)$ & $0.91(-34.9)$ & $1.08(-46.2)$ & 22.8 & 23.0 \\
\hline San Antonio, TX & 0.39 (41.3) & $0.45(20.4)$ & $0.49(16.0)$ & $0.59(-4.9)$ & $0.60(-3.3)$ & $0.68(-17.1)$ & $0.85(-28.6)$ & $1.03(-42.5)$ & 29.9 & 30.1 \\
\hline Victoria, TX & 0.39 (41.9) & $0.45(21.0)$ & $0.49(16.5)$ & $0.58(-4.4)$ & $0.59(-2.7)$ & $0.68(-16.5)$ & $0.84(-28.1)$ & $1.02(-41.9)$ & 27.4 & 27.7 \\
\hline
\end{tabular}

MEA monoethanolamine, $\boldsymbol{D I}$ direct injection, CF centrifuge, CFP chamber filter press, NGD natural gas drying, WHD waste heat drying.

* Values in parentheses represent Net Life Cycle GHG Emissions expressed in unit of $\left(\mathrm{g} \mathrm{CO}_{2}\right.$ eq/MJ-Biomass). Values outside of parentheses represent EROI $\mathrm{fossil}_{\text {. The }}$ last two columns represent water demand (WD).

${ }^{1}$ The results for the WD are presented in units of (liters/MJ-biomass).

more fossil energy is consumed than bioenergy produced during biomass production. Only one out of the eight examined production pathways, (scenario $\mathrm{H}$ ), was found to yield an $\mathrm{EROI}_{\text {fossil }}$ greater than 1. Furthermore, scenario $\mathrm{H}$ was found to have a barely positive energy balance and is plagued with high technological uncertainty. Additionally, the results reveal that net life cycle GHG emissions are negative for various biomass production pathways, indicating that microalgae sequester more GHGs than are emitted during biomass production via these pathways.

A particularly noteworthy observation from Table 1 is that $\mathrm{EROI}_{\text {fossil }}$ values are relatively location invariant, indicating that changes in regional electricity mix and climatological factors are negligible as compared to other fossil energy intensive processes such as algal biomass drying. Although cultivation locations, such as Arizona, have significantly higher algal growth rates as compared to other examined locations, the energy and GHG impact of producing microalgal feedstock on a per MJ basis for a given production pathway is not significantly different amongst examined locations. However, locations with high aerial biomass productivity may be preferable for algae cultivation as they are capable of generating a greater amount of microalgal biomass feedstock per unit surface area, thus reducing potential land use impacts.

\section{Direct water demands}

Table 1 provides direct WDs for the examined cultivation locations. The results from Table 1 indicate that the WDs of algae cultivation are highly sensitive to geographic location. Moreover, variation in production pathway has negligible effects upon the direct WDs, a trend directly opposite to that observed for $\mathrm{EROI}_{\text {fossil }}$ and net life cycle GHG emissions. Further analysis indicates that evaporative losses and process water lost during the harvesting stage accounts for the majority of the direct WDs. Additionally, the large variance observed in the direct WDs is primarily due to the large variation in location specific rates of evaporation and precipitation. 
Additional details on various contributors to water demand for Phoenix, AZ is available in supporting information (see Additional file 1).

\section{Detailed analysis: Phoenix, Arizona}

Figure 2 presents the fossil energy inputs normalized per unit of biomass energy output for biomass production pathways for Phoenix, Arizona. For each production pathway, input indicates the amount of primary fossil energy consumed for the production of one $\mathrm{MJ}$ of biomass energy, output. The results highlight that $\mathrm{CO}_{2}$ procurement, drying, and fertilizer inputs constitute the largest share of the fossil energy consumption in algal biomass production. In addition these parameters were also found to comprise a high percentage of total life cycle GHG emissions in biomass production as indicated in Figure 3.

\section{Pure $\mathrm{CO}_{2}$ vs. flue gas}

The results of this study indicate that the use of MEAbased $\mathrm{CO}_{2}$ capture to purify industrial flue gas is energy intensive, primarily due to the high steam requirements for the MEA process. For Phoenix AZ, the primary energy required for the direct injection of industrial flue gas is equivalent to $3.3 \%$ of total produced bioenergy. Additionally, life cycle GHG emissions for the direct injection of flue gas were determined to be $2.31 \mathrm{~g} \mathrm{CO}_{2}$ eq./MJ-biomass. While microalgae's potential to utilize flue gas as a source of $\mathrm{CO}_{2}$ has been extensively cited in the literature $[62,63]$, it remains uncertain if the presence of flue gas will have detrimental effects upon the algae culture $[64,65]$. There is potential concern that industrial flue gases may contain heavy metals, which may pose serious problems in downstream algal biomass upgrading to transportation fuels. Furthermore, industrial scale operational logistics for the direct injection of flue gas have yet to be evaluated. Therefore, while the utilization of industrial flue gas has the potential to decrease the high energy and environmental cost associated with $\mathrm{CO}_{2}$ procurement, the feasibility of direct injection of flue gas on an industrial scale remains questionable, and its effects upon the algal culture are highly uncertain.

\section{Chamber filter press vs. centrifuge}

Chamber filter presses were found to be a more energy efficient method of dewatering, producing a higher concentration biomass (w/w) at a lower energy and environmental cost as compared to centrifugation. For Phoenix, Arizona, switching from centrifugation to chamber filter presses was found to decrease the primary energy consumption of dewatering from approximately $21.4 \%$ to $2.4 \%$ of total produced bioenergy and decrease related life cycle GHG emissions from 15.0 to $1.65 \mathrm{~g} \mathrm{CO}_{2} \mathrm{eq} /$ MJ-biomass, respectively.

\section{Natural gas based drying vs. waste heat drying}

Natural gas based drying of microalgae was determined to be a critical energy and GHG burden in biomass production. For scenarios utilizing chamber filter presses, the primary energy required for natural gas drying of the microalgae is equivalent to $73 \%$ of total produced bioenergy, resulting in life cycle GHG emissions of $37.55 \mathrm{~g} \mathrm{CO}_{2}$ eq./MJ-biomass. For centrifugation-based pathways the primary energy required for natural gas drying is approximately $87 \%$ of total produced bioenergy, with corresponding life cycle GHG emissions of $44.62 \mathrm{~g} \mathrm{CO}_{2}$ eq./MJ-biomass. Given the high energy and environmental impacts of natural gas based drying, alternate and effective dewatering and drying strategies must be realized. Prior studies have suggested that utilizing waste heat from flue gas streams emanating from colocated power plants could be used to offset algal

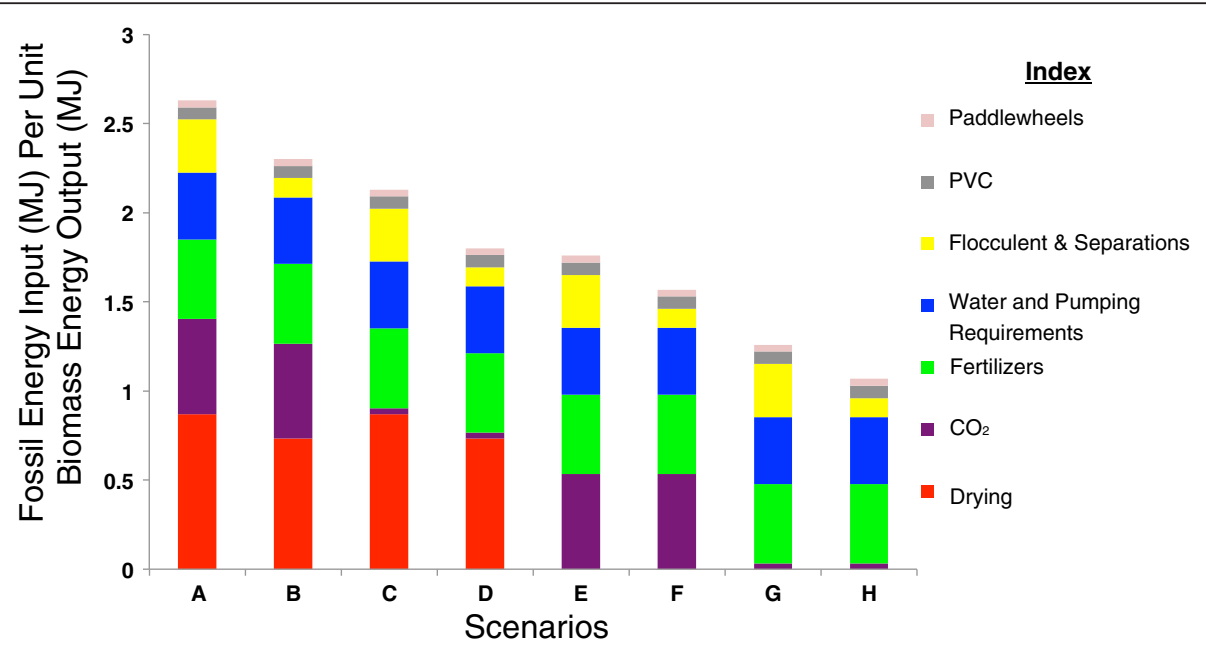

Figure 2 Life cycle energy analysis for Phoenix, Arizona. Detailed description for scenarios A-H are provided in Table 1. 


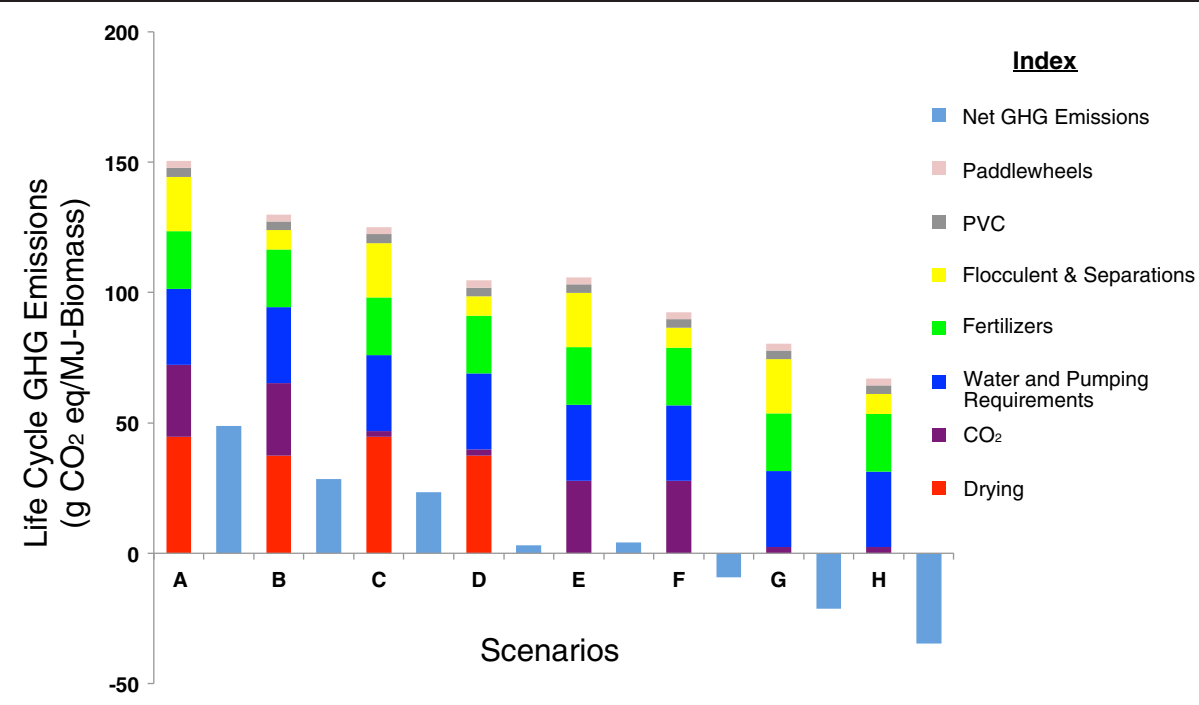

Figure 3 Life cycle GHG analysis for Phoenix, Arizona. Detailed description for scenarios A-H are provided in Table 1.

drying requirements. While the use of this waste heat could considerably decrease algae's environmental and energy impacts, the technical feasibility and practicality of such a system remains uncertain. Additionally, the quality of the waste heat, and thus its ability to do useful work, are important parameters that may constrain the effectiveness of this approach.

\section{Sensitivity analysis}

A sensitivity analysis was conducted to examine how variations in model parameters influence net life cycle GHG emissions and $\mathrm{EROI}_{\text {fossil }}$ for algal biomass production. Figure 4 presents tornado plots for $\mathrm{EROI}_{\text {fossil }}$ values and net life cycle GHG emissions for Phoenix, Arizona. The results in Figure 4 reveal the relative importance and sensitivity of EROI fossil $_{\text {and life cycle GHG emissions }}$ to system parameters, and confirm that the cultivation and harvesting of microalgae is highly sensitive to algal composition, $\mathrm{CO}_{2}$ procurement, algal growth rates, and drying method. Furthermore, the results suggest that improvements in algae-to-energy production are likely to occur via greater control over algal compositional inputs and advancements in algal drying technologies. Model parameters for sensitivity analysis are provided in Table 2.

\section{Conclusions}

The results of this study indicate that the life cycle energy and GHG performance of algal biomass production is highly dependent on the production pathway. Analysis reveals that 5 out of the 8 examined production pathways are net GHG negative, while only 1 out of the 8 scenarios have a positive energy balance. Generally, we find that the production of microalgae biomass is energy intensive (reflected in the low EROI), however, the process may be net GHG negative. Furthermore, the life cycle energy balance is found to be relatively location invariant. Contrarily, microalgae's direct WDs were found to be highly sensitive to geographic location, primarily due to differences in annual precipitation and evaporation. Although regions with high biomass productivity are often touted as optimal locations for microalgae cultivation, they are characteristically found in arid regions with lowfreshwater availability. Therefore, quantifying and evaluating the economic and environmental impacts of large scale algae production upon water resources at both the regional and global level is a critical issue that needs to be addressed if algae is to be a commercial source of sustainable bioenergy. Issues of water scarcity, land use change, and land availability may prove to be the constraining factors in commercial bioenergy production. While the direct $\mathrm{WD}, \mathrm{EROI}_{\text {fossil }}$, and net life cycle GHG emissions are important criteria for evaluating biomass feedstocks and biofuels, other sustainability indicators must also be considered to ensure that microalgal derived biofuels do not shift the environmental impacts across their life cycle from one impact category to another.

Thermodynamic constraints dictate that downstream processing and conversion of biomass feedstocks into fuels may only result in further reduction of $\mathrm{EROI}_{\text {fossil }}$. Therefore, the EROI $\mathrm{I}_{\text {fossil }}$ values for biomass feedstocks may represent an upper bound, or maximum $\mathrm{EROI}_{\text {fossil }}$ value, for fuels generated via these feedstocks. This study found that the majority of examined microalgal biomass production pathways had a negative energy balance. Subsequently, only one production pathway $(\mathrm{H})$ yielded an $\mathrm{EROI}_{\text {fossil }}$ value greater than 1, and was found to be only marginally energy positive and plagued with high technological uncertainty, and thus is an indicator that a 


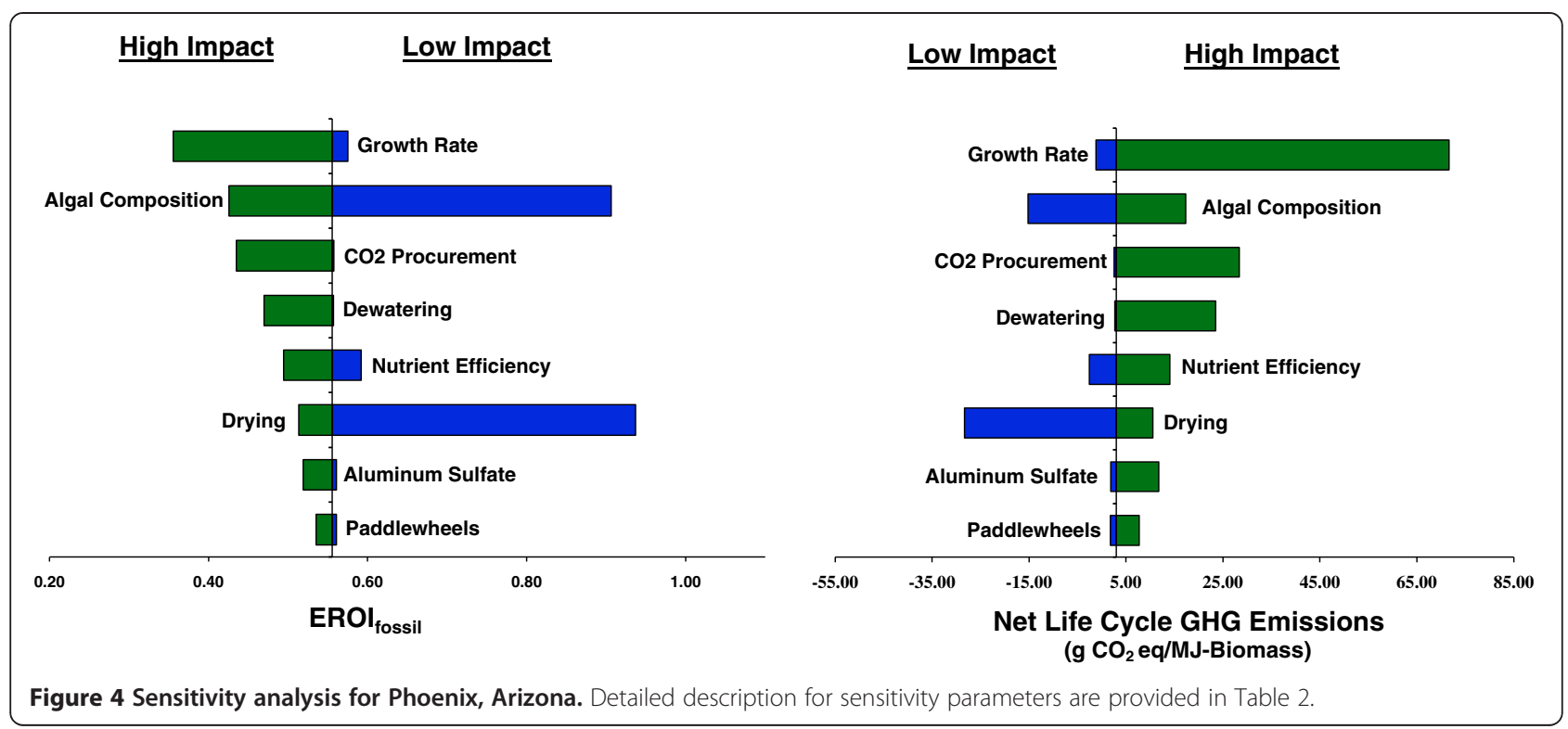

different approach is necessary. An alternate technological route utilizing auto-flocculation [66], cross flow filtration [67], chamber filter press, as well as natural gas based drying and waste heat drying for producing dried algal biomass was evaluated. Recent studies have suggested that cross flow filtration (CFF) is a low-energy intensive technology that can be used to dewater the algae culture [67], and has many advantages over conventional centrifugation, dissolved air and/or froth flotation [68], and pressure filtration. This technological route may be favorable, as it does not rely on a coagulant for biomass production and uses low-energy dewatering strategies. The EROI $_{\text {fossil }}$ and life cycle GHG emissions for this pathway are comparable to scenario $(\mathrm{H})$, detailed results are provided in the supporting information (see Additional file 1).

Improvements in dewatering technologies represent one avenue to decrease microalgae's high energy burden. For example, in recent years, geosynthetic membranes designed for containment and dewatering of various industrial wastes, have seen commercial application in both wastewater treatment and other industrial processes $[69,70]$. As these geosynthetic membranes can provide both a low energy and low cost method for dewatering, they may have significant application in algae cultivation. In addition, after use, these geosynthetic textiles can be recycled and may have a variety of applications in both construction and other industries.

Researchers have suggested coupling wastewater treatment with algae cultivation to reduce the nutrient and freshwater inputs required for algal biomass production and resource inputs necessary for wastewater treatment $[16,71,72]$. While the use of wastewater for algal biomass cultivation could help minimize algal nutrient requirements, as well as decrease algae's water footprint [27], studies suggest that waste streams may have relatively

Table 2 Critical parameters for sensitivity analysis

\begin{tabular}{|c|c|c|c|}
\hline \multicolumn{4}{|c|}{ Sensitivity analysis } \\
\hline Parameters & Low impact & Baseline & High impact \\
\hline Algal Composition [\% Lipid/Carb/Protein] & $50 / 40 / 5$ & $20 / 25 / 50$ & $5 / 20 / 70$ \\
\hline Aluminum Sulfate $\left[\mathrm{g} / \mathrm{m}^{3}\right]$ & 80 & 100 & 250 \\
\hline $\mathrm{CO}_{2}$ Procurement $[\mathrm{N} / \mathrm{A}]$ & $\begin{array}{c}\text { Flue gas }(\mathrm{Dl}) \\
{\left[20 \% \text { decrease } \mathrm{CO}_{2} \text { injected }\right]}\end{array}$ & Flue gas (DI) & Pure $\mathrm{CO}_{2}(\mathrm{MEA})$ \\
\hline Dewatering $[\mathrm{N} / \mathrm{A}]$ & CFP [20\% decrease electricity consumption] & CFP & CF \\
\hline Drying $[N / A]$ & WHD & NGD & $\begin{array}{c}\text { NGD } \\
\text { [20\% increase NG consumption] }\end{array}$ \\
\hline Growth Rate $\left[\mathrm{g} / \mathrm{m}^{2}\right.$-day $]$ & 35 & 25 & 5 \\
\hline Nutrient Uptake [\%] & 100 & 75 & 50 \\
\hline Paddlewheels $\left[\mathrm{MJ} / \mathrm{m}^{2}\right.$-day $]$ & 36 & 65 & 180 \\
\hline
\end{tabular}


low concentrations of both nitrogen and phosphate and thus provide only minor fertilizer offsets [15]. Therefore, the potential of wastewater effluent to offset fertilizer requirements needs further evaluation and validation. Research has suggested that the use of saltwater algae cultures may mitigate algae's water footprint, however; further research is needed to understand and quantify the potential tradeoffs between sourcing saltwater, land availability, proximity to $\mathrm{CO}_{2}$ source, etc. Coupling Geographical Information Systems (GIS) with systems analysis for a realistic evaluation of potential synergies between available land and waste streams (flue gas, wastewater, saltwater) can shed light on the feasibility of large-scale microalgal biomass production [73].

Anaerobic digestion of residual de-oiled biomass (post lipid extraction) has also been suggested as a means of increasing the energy performance of the algae-to-energy system $[35,74]$. A downfall in this process configuration is that lipid extraction of microalgae feedstock with presentday commercial technology (dry extraction) requires algae to be dried to approximately $90 \%(\mathrm{w} / \mathrm{w})$, and therefore may be constrained by the energy considerations presented in this study. While the allure of algae based energy is its potential to act as a replacement for traditional transportation fuels, biogas production via anaerobic digestion of the entire algal biomass may have the potential for higher energy yields [75]. One unique advantage of anaerobic digestion is its ability to process wet input streams, and therefore is not limited by algal drying requirements. In addition, recycling of anaerobic digestate may offset a portion of algal nutrient requirements. However, further investigation of the life cycle environmental impacts and benefits of such a system is necessary before a statement can be issued.

This study highlights the importance of systems analysis of emerging algal technologies. Although the need for systems analysis is understood, it receives little attention at early stages of research, often leading to unfounded technological exuberance and optimism. A systems approach with life cycle thinking can test, ground the claims, and assess the environmental sustainability of emerging technologies. Furthermore, systems analysis can aid in identifying technological bottlenecks and sources of process inefficiencies along the supply chain before they become embedded. While industrial symbiosis via the use of wastewater or industrial flue gas and various other synergies have the potential to offset algae's high cultivation and harvesting costs, with each additional interdependent synergistic technology comes a level of complication that may challenge the performance, reliability, resilience, and viability of the system. The most efficient theoretical system in the end may not provide a practical solution. High-level evaluation of these synergistic opportunities and logistics must be performed in order to assess the commercial viability of algal biofuel systems. As an emerging field, there are many opportunities to enhance the potential of microalgae as an energy source. Alternative production scenarios and technologies may have the potential to reduce the critical demands of microalgal biomass production, and should be considered to make algae a viable and more efficient biofuel alternative.

\section{Additional file}

\begin{abstract}
Additional file 1: Supporting Info for Microalgae biomass production pathways - Evaluation of life cycle environmental impacts.pdf Detailed description of the modeling parameters, assumptions, and data used in this study can be found in the supporting document accompanying this article. The supporting information can be accessed free of charge via the journal's website.
\end{abstract}

\section{Abbreviations}

CF: Centrifugation; CFF: Cross flow filtration; CFP: Chamber filter press; $\mathrm{CO}_{2}$ : Carbon dioxide; DI: Direct injection of flue gas; DOE: Department of energy; eGRID: Emission and generation resource integrated database; EISA: Energy independence and security act; EROI: Energy return on invenment; GHG: Greenhouse gas; GIS: Geographic information systems; ha: Hectare; LCA: Life cycle assessment; LHV: Lower heating value; MEA: Monoethanolamine; MJ: Megajoule; NG: Natural gas; NGD: Natural gas drying; NOAA: National oceanic and atmospheric administration; NSRD: National solar radiation database; NWS: National weather service; ORP: Open raceway pond; PBR: Photobioreactor; PVC: Polyvinyl chloride; US: United States; USLCI: United States life cycle inventory; WD: Water demands; WHD: Waste heat drying; WWTP: Wastewater treatment plant; w/ w: Weight per weight.

\section{Competing interests}

The authors declare that they have no competing interests.

\section{Authors' contributions}

GGZ constructed the algae life cycle model, analyzed the results, and wrote the manuscript. VK coordinated the study, assisted/guided in the development and analysis of the life cycle model, and reviewed the manuscript. Both authors read and approved the final manuscript.

\section{Acknowledgements}

This research was supported in part by the Mascaro Center for Sustainable Innovation at the University of Pittsburgh.

Received: 11 March 2013 Accepted: 13 June 2013

Published: 20 June 2013

\section{References}

1. Sims REH, Mabee W, Saddler JN, Taylor M: An overview of second generation biofuel technologies. Bioresour Technol 2010, 101:1570-1580.

2. Greenwell H, Laurens L, Shields R, Lovitt R, Flynn K: Placing microalgae on the biofuels priority list: a review of the technological challenges. $J R$ Soc Interface 2010, 7:703-726.

3. Wijfels RH, Barbosa MJ: An Outlook on Microalgal Biofuels. Science 2010, 329:796-799.

4. Chisti $Y$ : Response to reijnders: do biofuels from microalgae beat biofuels from terrestrial plants? Trends Biotechnol 2008, 26:351-352.

5. Chisti Y: Biodiesel from microalgae. Biotechnol Adv 2007, 25:13.

6. Dismukes GC, Carrieri D, Bennette N, Ananyev GM, Posewitz MC: Aquatic phototrophs: efficient alternatives to land-based crops for biofuels. Curr Opin Biotechnol 2008, 19:235-240.

7. Malcata FX: Microalgae and biofuels: a promising partnership? Trends Biotechnol 2011, 29:542-549. 
8. Williams PJB, Laurens LML: Microalgae as biodiesel \& biomass feedstocks: review \& analysis of the biochemistry, energetics \& economics. Energ Environ Sci 2010, 3:554-590.

9. Chisti Y: Biodiesel from microalgae beats bioethanol. Trends Biotechnol 2008, 26:126-131.

10. Sissine F: Energy Independence and Security Act of 2007: A Summary of Major Provisions; Congressional Research Service Report for Congress, Order Code RL34294. Washington, DC; 2007:22

11. John S, et al: A look back at the U.S. Department of Energy's Aquatic Species Program [electronic resource] : biodiesel from algae. Golden, Colo: National Renewable Energy Laboratory; 1998

12. Huntley M, Redalje D: CO2 Mitigation and renewable Oil from photosynthetic microbes: a New appraisal. Mitig Adapt Strat Glob Change 2007, 12:573-608.

13. Brentner LB, Eckelman MJ, Zimmerman JB: Combinatorial life cycle assessment to inform process design of industrial production of algal biodiesel. Environ Sci Technol 2011, 45:7060-7067.

14. Brune DE, Lundquist TJ, Benemann JR: Microalgal Biomass for. Potential for Replacement of Fossil Fuels and Animal Feeds. ASCE: Greenhouse Gas Reductions; 2009.

15. Clarens AF, Nassau H, Resurreccion EP, White MA, Colosi LM: Environmental impacts of algae-derived biodiesel and bioelectricity for transportation. Environ Sci Technol 2011, 45:7554-7560.

16. Clarens AF, Resurreccion EP, White MA, Colosi LM: Environmental life cycle comparison of algae to other bioenergy feedstocks. Environ Sci Technol 2010, 44:1813-1819.

17. Collet P, Hélias A, Lardon L, Ras M, Goy R-A, Steyer J-P: Life-cycle assessment of microalgae culture coupled to biogas production. Bioresour Technol 2011, 102:207-214

18. Jorquera O, Kiperstok A, Sales EA, Embiruçu M, Ghirardi ML: Comparative energy life-cycle analyses of microalgal biomass production in open ponds and photobioreactors. Bioresour Technol 2010, 101:1406-1413.

19. Kadam KL: Microalgae production from power plant flue gas: Environmental implications on life cycle basis; NREL/TP-510-29417. National Renewable Energy Laboratory; 2001.

20. Murphy CF, Allen DT: Energy-water nexus for mass cultivation of algae. Environ Sci Technol 2011, 45:5861-5868.

21. Shirvani T, Yan X, Inderwildi OR, Edwards PP, King DA: Life cycle energy and greenhouse gas analysis for algae-derived biodiesel. Energ Environ Sci 2011, 4:3773-3778.

22. Soratana K, Landis AE: Evaluating industrial symbiosis and algae cultivation from a life cycle perspective. Bioresour Technol 2011, 102:6892-6901.

23. Stephenson AL, Kazamia E, Dennis JS, Howe CJ, Scott SA, Smith AG Life-cycle assessment of potential algal biodiesel production in the united kingdom: a comparison of raceways and Air-lift tubular bioreactors. Energy Fuel 2010, 24:4062-4077.

24. Vasudevan $V$, Stratton RW, Pearlson MN, Jersey GR, Beyene AG, Weissman JC, Rubino M, Hileman J: Environmental performance of algal biofuel technology options. Environ Sci Technol 2012, 46:2451-2459.

25. Campbell PK, Beer T, Batten D: Life cycle assessment of biodiese production from microalgae in ponds. Bioresour Technol 2011, 102:50-56

26. Xu L, Brilman DWF, Withag JAM, Brem G, Kersten S: Assessment of a dry and a wet route for the production of biofuels from microalgae: Energy balance analysis. Bioresour Technol 2011, 102:5113-5122

27. Yang J, Xu M, Zhang XZ, Hu QA, Sommerfeld M, Chen YS: Life-cycle analysis on biodiesel production from microalgae: water footprint and nutrients balance. Bioresour Technol 2011, 102:159-165.

28. Li Y, Horsman M, Wu N, Lan CQ, Dubois-Calero N: Biofuels from microalgae. Biotechnol Prog 2008, 24:815-820.

29. Luo DX, Hu ZS, Choi DG, Thomas VM, Realff MJ, Chance RR: Life Cycle Energy and Greenhouse Gas Emissions for an Ethanol Production Process Based on Blue-Green Algae. Environ Sci Technol 2010, 44:8670-8677.

30. Batan L, Quinn J, Willson B, Bradley T: Net energy and greenhouse Gas emission evaluation of biodiesel derived from microalgae. Environ Sci Technol 2010, 44:7975-7980.

31. Khoo HH, Sharratt PN, Das P, Balasubramanian RK, Naraharisetti PK, Shaik S: Life cycle energy and $\mathrm{CO}(2)$ analysis of microalgae-to-biodiesel: preliminary results and comparisons. Bioresour Technol 2011, 102:5800-5807.
32. Agusdinata DB, Zhao F, lleleji K, DeLaurentis D: Life cycle assessment of potential biojet fuel production in the United States. Environ Sci Technol 2011, 45:9133-9143.

33. Chowdhury R, Viamajala S, Gerlach R: Reduction of environmental and energy footprint of microalgal biodiesel production through material and energy integration. Bioresour Technol 2012, 108:102-111.

34. Sander K, Murthy G: Life cycle analysis of algae biodiesel. The International Journal of Life Cycle Assessment 2010, 15:704-714.

35. Lardon L, Hélias A, Sialve B, Steyer J-P, Bernard O: Life-cycle assessment of biodiesel production from microalgae. Environ Sci Technol 2009, 43:6475-6481.

36. Schenk P, Thomas-Hall S, Stephens E, Marx U, Mussgnug J, Posten C, Kruse O, Hankamer B: Second generation biofuels: high-efficiency microalgae for biodiesel production. Bioenergy Research 2008, 1:20-43.

37. Ferreira AF, Marques AC, Batista AP, Marques PASS, Gouveia L, Silva CM: Biological hydrogen production by Anabaena sp. - Yield, energy and $\mathrm{CO} 2$ analysis including fermentative biomass recovery. Int J Hydrogen Energ 2012, 37:179-190.

38. Ferreira AF, Ortigueira J, Alves L, Gouveia L, Moura P, Silva CM: Energy requirement and $\mathrm{CO} 2$ emissions of bioH2 production from microalgal biomass. Biomass and Bioenergy 2013, 49:249-259.

39. Ferreira AF, Ribeiro LA, Batista AP, Marques PASS, Nobre BP, Palavra AMF, da Silva PP, Gouveia L, Silva C: A biorefinery from Nannochloropsis sp. microalga - Energy and $\mathrm{CO} 2$ emission and economic analyses. Bioresour Technol 2013, 138:235-244.

40. Xu L, Weathers PJ, Xiong XR, Liu CZ: Microalgal bioreactors: Challenges and opportunities. Eng Life Sci 2009, 9:178-189.

41. Benemann, JR, Oswald, PI: Systems and economic analysis of microalgae ponds for conversion of CO2 to biomass-Final report; DOE/PC/93204-T5 Department of Energy, Pittsburgh Energy Technology Center 1996.

42. NREL: National solar radiation database (1961-1990). National Renewable Energy Laboratory, Ed. Golden, CO; 1994

43. Harmelen T, Oonk H: Microalge biofixation process: applications and potential contributions to greenhouse gas mitigation options. Apeldoorn, The Netherlands: TNO Built Environment and Geosciences; 2006

44. Uduman N, Qi Y, Danquah MK, Forde GM, Hoadley A: Dewatering of microalgal cultures: A major bottleneck to algae-based fuels. J. Renew. Sustain. Energy 2010, 2(1):012701-15.

45. Matos CT, Santos M, Nobre BP, Gouveia L: Nannochloropsis sp. biomass recovery by Electro-Coagulation for biodiesel and pigment production. Bioresour Technol 2013, 134:219-226.

46. Goldman JC: Outdoor algal mass-cultures.2. photosynthetic yield limitations. Water Res 1979, 13:119-136.

47. Weyer KM, Bush DR, Darzins A, Willson BD: Theoretical maximum algal Oil production. Bioenergy Research 2010, 3:204-213.

48. Becker EW: Micro-algae as a source of protein. Biotechnol Adv, 25:207-210.

49. Power Profiler. http://www.epa.gov/cleanenergy/energy-and-you/how-clean. html.

50. Kadam KL: Environmental implications of power generation via coal-microalgae cofiring. Energy 2002, 27:905-922.

51. Mohn FH: Experiences and Strategies in the recovery of biomass from mass cultures of microalgae. Amsterdam: Elsevier; 1980.

52. Ecoinvent Centre: Ecoinvent data v2.0. Swiss Centre for Life Cycle Inventories, Ed. Dubendorf; 2007.

53. Deru MP: NREL U.S. Life Cycle Inventory Database Roadmap; NREL Report No. BR-550-45153. National Renewable Energy Laboratory, U.S. Dept. of Energy: Golden, CO; 2009:80401.

54. King CW, Webber ME: Water intensity of transportation. Environ SCi Technol 2008, 42:7866-7872.

55. Gerbens-Leenes PW, Hoekstra AY, van der Meer T: The water footprint of energy from biomass: a quantitative assessment and consequences of an increasing share of bio-energy in energy supply. Ecol Econ 2009, 68:1052-1060

56. Dominguez-Faus R, Powers SE, Burken JG, Alvarez PJ: The water footprint of biofuels: a drink or drive issue? Environ Sci Technol 2009 43:3005-3010.

57. Chiu Y-W, Walseth B, Suh S: Water embodied in bioethanol in the united states. Environ Sci Technol 2009, 43:2688-2692.

58. Gerbens-Leenes W, Hoekstra AY, van der Meer TH: The water footprint of bioenergy. Proc Natl Acad Sci 2009, 106:10219-10223. 
59. Shuttleworth WJ: Putting the'vap'into evaporation. Hydrology and Earth System Sciences Discussions 2007, 11(1):210-244.

60. NOAA: Monthly Average Precipitation. National Climatic Data Center, National Oceanic and Atmospheric Administration; 2006.

61. Weissman JC, Goebel R: Design and analysis of microalgal open pond systems for the purpose of producing fuels: a subcontract report. USA: Solar Energy Research Inst., Golden, CO; 1987.

62. Benemann JR: $\mathrm{CO}_{2}$ mitigation with microalgae systems. Energy Conv Manag 1997, 38:S475-S479.

63. Ho SH, Chen CY, Lee DJ, Chang JS: Perspectives on microalgal CO(2)emission mitigation systems - A review. Biotechnol Adv 2011, 29:189-198

64. Cho S, Lee D, Luong TT, Park S, Oh YK, Lee T: Effects of Carbon and Nitrogen Sources on Fatty Acid Contents and Composition in the Green Microalga, Chlorella sp 227. J Microbiol Biotechnol 2011, 21:1073-1080.

65. Lv JM, Cheng LH, Xu XH, Zhang L, Chen HL: Enhanced lipid production of Chlorella vulgaris by adjustment of cultivation conditions. Bioresour Technol 2010, 101:6797-6804

66. Sukenik A, Shelef G: Algal autoflocculation-verification and proposed mechanism. Biotechnol Bioeng 1984, 26:142-147.

67. Bhave R, Kuritz T, Powell L, Adcock D: Membrane-based energy efficient dewatering of microalgae in biofuels production and recovery of value added Co-products. Environ Sci Technol 2012, 46:5599-5606.

68. Hanotu J, Bandulasena HCH, Zimmerman WB: Microflotation performance for algal separation. Biotechnol Bioeng 2012, 109:1663-1673.

69. Jensen KR, Allen RP, Keys D: Water Remediation and Biosolids Collection System and Associated Methods. Washington DC; 2012. US Patent 20,120,228,232.

70. Mukhtar S, Wagner K; Gregory L: Field demonstration of the performance of a Geotube ${ }^{\oplus}$ dewatering system to reduce phosphorus and other substances from dairy lagoon effluent. Texas: Water Resources Institute. http://texaseden.org/ disaster-resources/wp-content/uploads/2011/05/field-demo-geotubedewatering-system-reduce-dairy-effluent.pdf 2009, 1:86145.

71. Bhatnagar A, Chinnasamy S, Singh M, Das KC: Renewable biomass production by mixotrophic algae in the presence of various carbon sources and wastewaters. Appl Energy 2011, 88:3425-3431.

72. Rawat I, Kumar RR, Mutanda T, Bux F: Dual role of microalgae: phycoremediation of domestic wastewater and biomass production for sustainable biofuels production. Appl Energy 2011, 88:3411-3424.

73. Fortier M-OP, Sturm BS: Geographic Analysis of the Feasibility of Collocating Algal Biomass Production with Wastewater Treatment Plants. Environ Sci Technol 2012, 46:11426-11434.

74. Sialve B, Bernet N, Bernard O: Anaerobic digestion of microalgae as a necessary step to make microalgal biodiesel sustainable. Biotechnol Adv 2009, 27:409-416.

75. Hughes A, Kelly M, Black K, Stanley M: Biogas from macroalgae: is it time to revisit the idea? Biotechnology for Biofuels 2012, 5:86.

\section{Submit your next manuscript to BioMed Central and take full advantage of:}

- Convenient online submission

- Thorough peer review

- No space constraints or color figure charges

- Immediate publication on acceptance

- Inclusion in PubMed, CAS, Scopus and Google Scholar

- Research which is freely available for redistribution 